\title{
Pathogenesis of pulmonary arterial hypertension: lessons from cancer
}

\author{
Christophe Guignabert' ${ }^{1,2}$, Ly Tu ${ }^{1,2}$, Morane Le Hiress ${ }^{1,2}$, Nicolas Ricard $^{1,2}$, \\ Caroline Sattler ${ }^{1,2,3}$, Andrei Seferian ${ }^{1,2,3}$, Alice Huertas ${ }^{1,2,3}$, Marc Humbert ${ }^{1,2,3}$ \\ and David Montani ${ }^{1,2,3}$
}

\begin{abstract}
Affiliations: 'INSERM UMRS 999, LabEx LERMIT, Centre Chirurgical Marie Lannelongue, Le Plessis Robinson, ${ }^{2}$ Université Paris-Sud, Le Kremlin-Bicêtre, and ${ }^{3} \mathrm{AP}-\mathrm{HP}$, Service de Pneumologie, DHU Thorax Innovation (DHU TORINOJ, Hôpital Bicêtre, Le Kremlin-Bicêtre, France.
\end{abstract}

Correspondence: D. Montani, Service de Pneumologie, DHU Thorax Innovation, Centre de Référence de l'Hypertension Pulmonaire Sévère, Hôpital Bicêtre, 78 rue du Général Leclerc, 94270 Le Kremlin-Bicêtre, France. E-mail: david.montanidu-psud.fr

ABSTRACT Although the causal pathomechanisms contributing to remodelling of the pulmonary vascular bed in pulmonary arterial hypertension $(\mathrm{PAH})$ are still unclear, several analogous features with carcinogenesis have led to the emergence of the cancer-like concept. The major similarities concern the altered crosstalk between cells from different tissue types, unexplained proliferation and survival of pulmonary smooth muscle and endothelial cells, the metabolic (glycolytic) shifts, and the association with the immune system. However, major differences between PAH and cancer exist, including the absence of invasion and metastasis, as well as the pathogenic genes involved and the degrees of angiogenesis impairment and genetic instability. It is clear that PAH is not a cancer, but this cancer-like concept has opened a new field of investigation and raises the possibility that antiproliferative and/or oncological drugs may exert therapeutic effects not only in cancer, but also in PAH. Such analogies and differences are discussed here.

0 @ERSpublications Intriguing analogies between PAH pathogenesis and carcinogenesis are observed, but crucial differences also exist http://ow.ly/pTS6D

\section{Introduction}

Pulmonary arterial hypertension (PAH) is a complex and progressive cardiopulmonary disorder, with poor prognosis and no curative options, characterised by elevated pulmonary vascular resistance (PVR) and pulmonary artery pressure (PAP) leading to right-heart failure and death [1-4]. The symptoms are nonspecific and include breathlessness, fatigue, weakness, angina and syncope. The combination of pulmonary vasoconstriction, in situ thrombosis and pulmonary arterial wall remodelling is largely responsible for the rise in PVR and PAP in patients with PAH, leading to progressive functional decline in patients despite current available therapeutic options.

Received: Sept 282013 | Accepted after revision: Oct 142013

Support statement: This work was funded, in part, by grants from the French National Institute for Health and Medical Research (INSERM), the Legs Poix (Chancellerie des Universités de Paris, Paris, France), and the French National Agency for Research (grant no. ANR_12_JSV1_0004_01). A. Huertas is supported by the 2010 Josso Award from the French Medical Research Foundation (Paris, France). A. Seferian is supported by the French PAH patient association HTAP France (Asnières Lès Dijon, France). C. Sattler is supported by the Fonds de Dotation "Recherche en Santé Respiratoire" (Paris, France).

Conflict of interest: Disclosures can be found alongside the online version of this article at err.ersjournals.com

Provenance: Submitted article, peer reviewed.

Copyright OERS 2013. ERR articles are open access and distributed under the terms of the Creative Commons Attribution Non-Commercial Licence 3.0. 


\section{Pathology of PAH}

Pulmonary vascular remodelling, occurring mostly in the small to mid-sized pulmonary arterioles $(<500 \mu \mathrm{m})$, is a hallmark of most forms of pulmonary hypertension (PH). Pulmonary vascular lesions occurring in patients with $\mathrm{PAH}$, as well as in animal models of $\mathrm{PH}$, take place sequentially and include, to varying degrees: abnormal muscularisation of distal and medial pre-capillary arteries, loss of pre-capillary arteries, thickening of the pulmonary arteriolar wall with concentric or eccentric laminar lesions, neointimal formation, fibrinoid necrosis, and the formation of complex lesions commonly named "plexiform lesions" [5]. This remodelling process involves changes in all three layers of the vessel wall (intima, media and adventitia) that are the consequence of cellular hypertrophy, hyperplasia, inflammation, altered energy metabolism, defects in cell differentiation and apoptosis, excessive migration, and accumulation of extracellular matrix components.

\section{Current understanding of PAH pathogenesis and pathophysiology}

An expanding body of knowledge has revealed the complex nature of these structural and functional changes in the pulmonary vasculature implicating unexplained proliferation, migration and survival of pulmonary vascular cells within the pulmonary arterial wall (i.e. smooth muscle cells (SMCs), myofibroblasts and endothelial cells). Although the causal PAH pathomechanisms are still largely unclear, important discoveries have been made including many disease-predisposing factors and/or contributing factors, such as inflammation, pulmonary endothelial dysfunction and aberrant cell proliferation in the vascular wall, as well as several gene mutations [3-5]. In recent years, the novel cancer-like concept for PAH has emerged and has its roots in intriguing in situ and in vitro observations [6, 7]. Among them: a monoclonal expansion of endothelial cells has been found in idiopathic forms of PAH when compared with endothelial cells found in lungs of patients with congenital heart malformations [8]; evidence has been obtained indicating instability of short DNA microsatellite sequences within plexiform lesions in idiopathic $\mathrm{PAH}$ [9]; the presence of somatic chromosome abnormalities in the lungs of patients with PAH and cultured cells has been reported [10]; when removed from their in vivo environment, pulmonary endothelial cells and SMCs derived from patients with PAH maintain their abnormal hyperproliferative, apoptosisresistant phenotype for a longer time than control cells [11-13]; and human pulmonary vascular cells derived from PAH patients exhibit an altered energy metabolism in situ and in vitro [14-19]. However, there are crucial differences between PAH pathogenesis and carcinogenesis, as will be discussed later (fig. 1 and table 1)[20, 21]. It is clear that a tumorigenic mechanism alone cannot fully explain PAH, but this cancer-like concept has opened a new field of investigation regarding the potential use of antiproliferative and/or oncological drugs in PAH. In this context, some drugs used in the treatment of cancer were recently tested in PAH [22-26]. It has been demonstrated that tyrosine kinase inhibitors (i.e. imatinib) may have potential benefits in PAH patients but their safety profile, and particularly severe side-effects, raise many concerns regarding their use in clinical practice $[25,26]$. Therefore, and as discussed in the following sections, there are reasons to continue clarifying the nature of the similarities and differences between the $\mathrm{PAH}$ pathogenesis and carcinogenesis.

\section{Current theories of carcinogenesis}

Carcinogenesis is a general term used to describe the process that results in the development of a malignant neoplasm. This process can be actively induced by exposure to chemicals, drugs, radiation or infectious biological agents, by heredity or in the context of immune disease; however, in most of the cases, the cause is unknown. Although several theories have been proposed, at present there is no generally accepted, unified theory of carcinogenesis as illustrated with the recent critical review and analysis of the 10 broad features "hallmarks of cancer" proposed by HANAHAN and WEINBERG (fig. 1a) [20, 21]. The gene mutation theory (or the somatic mutation theory (SMT)) and the integrative states are the two most widely accepted theories in the scientific community $[20,21,27]$. The first theory states that cancer begins with a genetic change within one single cell (initiation event) followed by its clonal expansion to generate malignant cells, and is supported by a vast body of evidence such as: evidence of genomic instability; inherited genetic conditions; existence of carcinogens as known mutagens; and activation of cellular oncogene expression by adjacent viral genomes. However, this theory does not explain several key aspects of carcinogenesis, including tumour heterogeneity and aneuploidy, as well as the interval between the initiation event and the development of tumour. In addition, only a subset of the large number of somatic alterations actively contributes to tumour initiation and maintenance. The alternative theory, also known as the tissue organisation field theory (TOFT) [27], supports the notion that cancer is a tissue-based disease due to alterations of the reciprocal interactions among cells and between cells and their extracellular matrix. This theory also takes into account the notion that proliferation and motility are the default state of all cells, and that cells are organised to form tissues, organs and organ systems. In addition to the SMT and TOFT theories, there are also alternative theories including the aneuploidy theory, the oncogene and tumour 


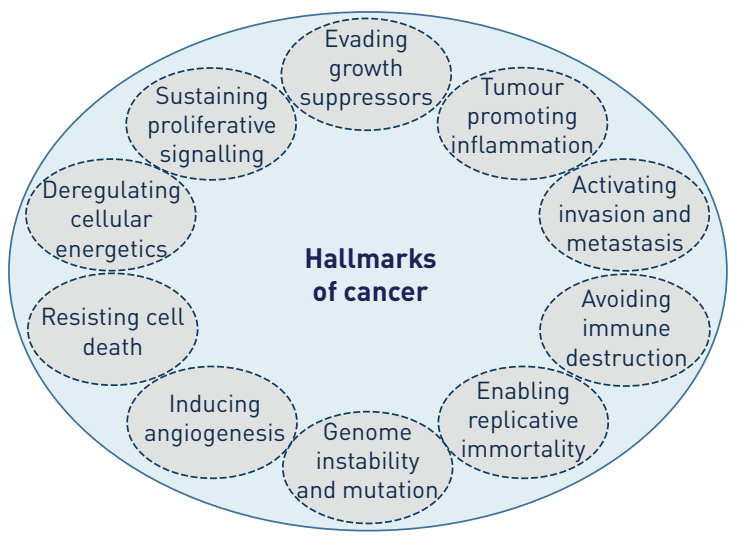

b)

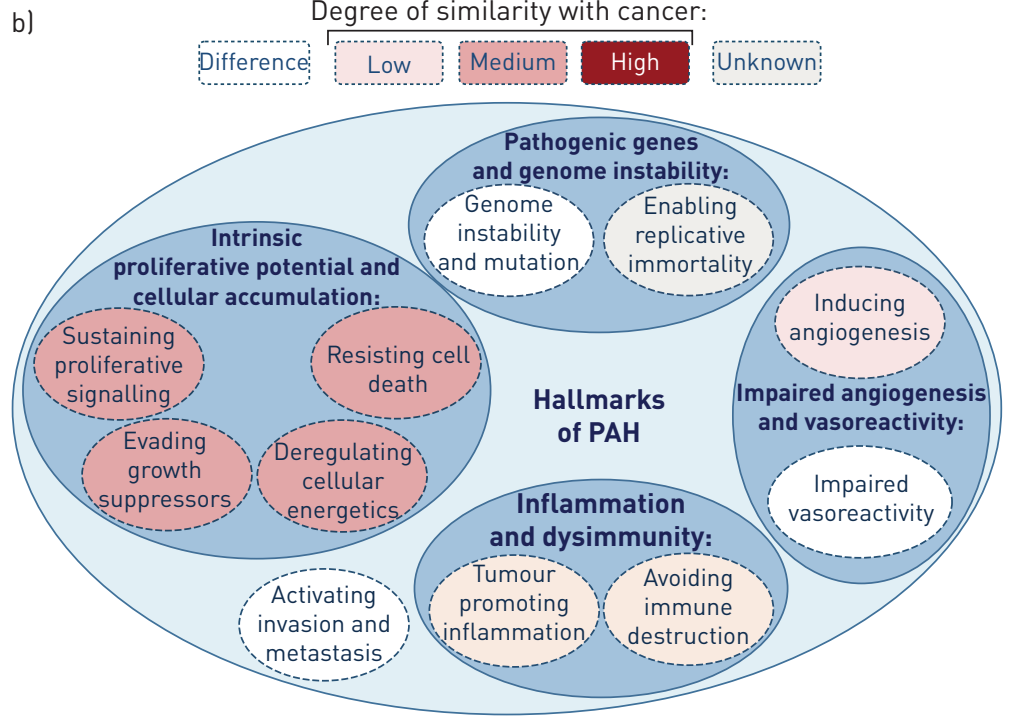

FIGURE 1 The "hallmarks of cancer" proposed by HANAHAN and WEINBERG [20, 21]. a) The six hallmark capabilities originally proposed in 2000 together with the four additional hallmarks proposed in 2011. b) Although pulmonary arterial hypertension (PAH) shares several cancer capabilities, the degree of similarity varies. Furthermore, these capabilities can be markedly different to those observed in cancer; in particular, neither invasion nor metastasis has been observed in $\mathrm{PAH}$. In addition, these features found in PAH also appear to contribute to the disease pathogenesis with different levels of importance.

suppressor theory, the epigenetic theory, the stem cell theory, and the multi-stage, multi-mechanism theory. All these hypotheses combined with the SMT and TOFT theories gave a plausible explanation for the long latent period from carcinogen treatment to cancer development, as well as for the clonality aspect, which underlies the development of neoplastic disease.

\section{Major differences and analogous features between cancer and PAH}

Several intriguing analogies between $\mathrm{PAH}$ pathogenesis and carcinogenesis have been observed, but crucial differences also exist (figs 1 and 2).

\section{Tissue invasion and metastasis}

Cancer cells are aggressive (cells rapidly reproduce despite restriction of space and nutrients, or signals sent to stop reproduction), invasive (by destroying adjacent tissues), and/or metastatic (spread to other locations). As for benign tumour cells, these three malignant properties of cancer cells are not present in vascular PAH cells, which are self-limited in their growth, do not lose the contact inhibition property, and do not invade or metastasise.

\section{TABLE 1 Hallmarks of cancer}

\begin{tabular}{ll} 
Cancer hallmarks & Therapeutic targeting \\
\hline Evading growth suppressors & Cyclin-dependant kinase inhibitors \\
Sustaining proliferative signalling & EGFR inhibitors \\
Resisting cell death & Pro-apoptotic BH3 mimetics \\
Enabling replicative immortality & Telomerase inhibitors \\
Inducing angiogenesis & Inhibitors of VEGF signalling \\
Avoiding immune destruction & Immune activating anti-CTLA4 monoclonal antibody \\
Tumour promoting inflammation & Selective anti-inflammatory drugs \\
Genome instability and mutation & PARP inhibitors \\
Deregulating cellular energetics & Aerobic glycolysis inhibitors \\
Activating invasion and metastasis & Inhibitors of HGF/c-Met
\end{tabular}

EGFR: epithelial growth factor receptor; VEGF: vascular endothelial growth factor; CTLA4: cytotoxic T lymphocyte-associated antigen 4; PARP: poly ADP-ribose polymerase; HGF: hepatocyte growth factor. 


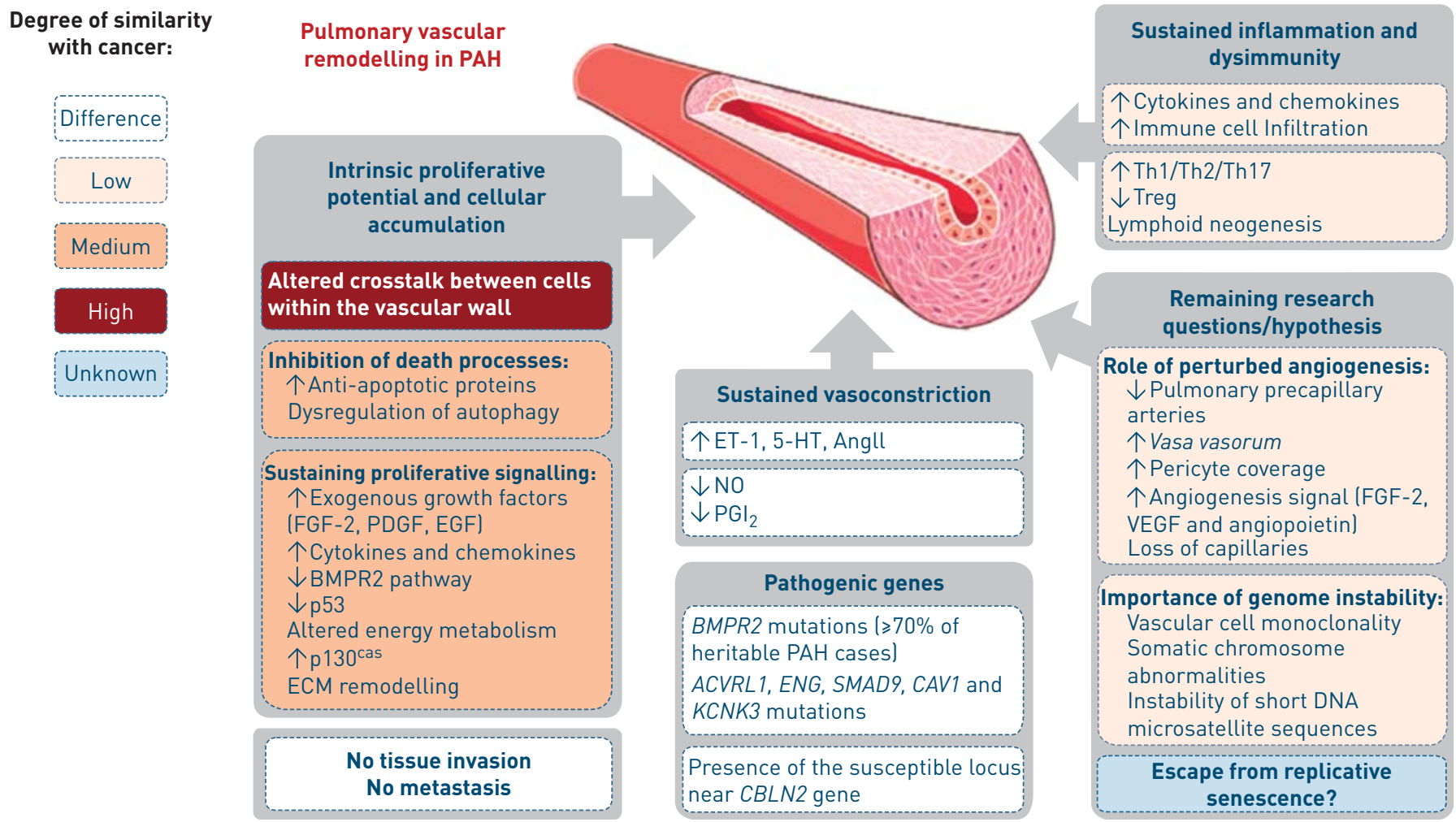

FIGURE 2 Pathogenic concepts of pulmonary arterial hypertension (PAH). The major differences and analogous features between cancer and PAH are highlighted. FGF: fibroblast growth factor; PDGF: platelet-derived growth factor; EGF: epidermal growth factor; BMPR2: bone morphogenetic protein receptor 2; ECM: extracellular matrix; ET-1: endothelin-1; 5-HT: serotonin; NO: nitric oxide; PGI 2 : prostacyclin; Th: T-helper cell; Treg: regulatory T-cell; VEGF: vascular endothelial growth factor.

\section{Intrinsic proliferative potential and cellular accumulation}

Under physiological circumstances, the balance between proliferation and programmed cell death, usually in the form of apoptosis, is tightly regulated to ensure the integrity of organs and tissues. Modulation of this balance is crucial for development, tissue repair and tissue homeostasis; however, the underlying physiological mechanisms central to such modulation are still only partially understood. Both activation of proliferative signals and inhibition of death processes, which lead to survival, have been reported in several vascular proliferative diseases (i.e. atherosclerosis, post-angioplasty restenosis and vein graft disease) including PAH [11, 12, 28-31]. However, pulmonary vascular remodelling is an active process of structural change intrinsically linked to modification in cell growth, cell death, cell migration, cell differentiation, and the synthesis or degradation of extracellular matrix. This hyperplasia occurs in the pulmonary vasculature, partly in response to long-standing changes in haemodynamic conditions, and many of the vascular cells in pulmonary arterioles from patients with $\mathrm{PAH}$ are non-proliferating cells, even in complex pulmonary plexiform lesions. In addition, this vascular remodelling process involves all cell types within each of the three layers of the vessel wall, contrasting with the clonal expansion that is often observed in cancers.

Alterations in the cell proliferation machinery, particularly in the coordinated interaction of cyclins and cyclin-dependent kinases, are often found in tumour cells, contributing to inappropriate proliferation and promoting genetic instability. Currently, in PAH, there is no evidence that pulmonary vascular cells acquire the ability to reproduce without control. However, it is clear that pulmonary endothelial cells and SMCs derived from patients with PAH have a higher proliferative potential and are more prone to resist the induction of apoptosis when compared with control cells [11-13]. These observations explain the fact that interest has been growing in the potential use of anti-proliferative approaches in PAH [32]. We have recently reported that primary pulmonary endothelial cells generated from PAH lung specimens exhibit various intrinsic abnormalities and present a modified pro-proliferative, apoptotic-resistant phenotype. When compared with control cells, we found that both pulmonary endothelial cells and SMCs from patients with PAH have a more pronounced proliferation in response to fetal calf serum, fibroblast growth factor (FGF)-2, epidermal growth factor or platelet-derived growth factor, and are less sensitive to apoptosis induction by either serum deprivation or low doses of hydrogen peroxide and cycloheximide [11, 12]. 
Although we have shown that increased activity of the FGF-2 autocrine loop and over-activation of the adaptor protein $\mathrm{p} 130^{\mathrm{cas}}$ are among the mechanisms needed to acquire this altered endothelial phenotype in $\mathrm{PAH}$, the exact nature of such alterations remains only partially understood $[11,12]$. Consistent with this apoptotic resistant vascular cell phenotype, several in situ observations were obtained showing that pulmonary vascular cells from PAH patients exhibit abnormal increases in the key anti-apoptotic factors $\mathrm{Bcl}-\mathrm{xL}, \mathrm{Bcl}-2$ and survivin $[11,12,33]$. Excessive release of growth factors that are encrypted in the extracellular matrix, and/or modification of growth factor production, receptor expression and/or alterations in the intracellular mitogenic signals have also been reported to have an important role in the disease. Their inhibition by specific inhibitors, such as tyrosine kinase inhibitors (i.e. imatinib, gefitinib and dovitinib), have been shown to exert beneficial effects in animal models of PH [11,34-36]. However, further efforts still need to be made in order to establish the long-term safety and efficacy of these antiproliferative approaches in PAH and their potential additive benefit with other drugs. Furthermore, recent evidence also suggests that a Warburg phenotype (a chronic shift in energy production from mitochondrial oxidative phosphorylation to glycolysis) of pulmonary vascular cells is present and may participate in the pathogenesis [14-19]. Restitution of oxidative metabolism with the use of dichloroacetate (DCA) has been shown to be efficient in several animal models of PH [17, 19, 37]. Inhibition of pyruvate dehydrogenase kinase by DCA frees up the mitochondrial gate-keeping enzyme pyruvate dehydrogenase, which is then able to convert pyruvate to acetyl-CoA and initiate normal oxidative phosphorylation via the Krebs cycle. However, DCA has a wide spectrum of effects. For example, DCA also partly corrects dysfunctions related to abnormal activation of the HIF- $1 \alpha-\mathrm{Kv} 1.5$ axis, production of reactive oxygen species, fragmentation and/ or hyperpolarisation of the mitochondrial reticulum. Since mitochondrial fatty acid oxidation contributes to the "Randle cycle" inhibition of glucose utilisation, the inhibition of fatty acid oxidation has also been shown to prevent this metabolic shift and limit the proliferative and anti-apoptotic cell phenotype observed in PH [18]. Whether or not acquisition and/or maintenance of this abnormal vascular cell phenotype is a cause or a consequence of this characteristic progressive pulmonary vascular obstruction in $\mathrm{PAH}$ is unknown. Thus, several unanswered questions remain regarding its nature and true importance in this disease. Importantly, our group has underscored altered crosstalks between cells within the vascular wall $[12,38-40]$. The dysfunctional endothelium in PAH displays, to varying degrees, an imbalanced production of several mediators leading towards an excess of vasoconstriction, smooth muscle hyperplasia and pulmonary vascular remodelling. We obtained evidence that pulmonary endothelial cells from patients with idiopathic PAH release excessive amounts of soluble growth factors and cytokines that are able to act on SMCs. Paracrine overproduction of endothelin-1, serotonin [39], angiotensin II [38, 41] and FGF-2 [11, 12, 34] contributes to the increased SMC proliferation. Therefore, restoration of an appropriate endothelial cell-SMC crosstalk may represent another strategy for inhibition of pro-migratory and pro-proliferative signalling pathways in $\mathrm{PAH}$ [32]. As discussed in the following section, an abnormal crosstalk between altered immunity and vascular wall dysfunction also participates in pulmonary vascular remodelling in PAH [42, 43]. Taken together, these elements strongly support the notion that anti-proliferative strategies could offer a novel approach for the treatment of $\mathrm{PAH}$, by downregulating the progression of the disease and reversal of pulmonary vascular remodelling. Therefore, further studies are needed to better understand the mechanisms underlying this abnormal over-activation of some growth factor-stimulated signalling pathways in $\mathrm{PAH}$, and to identify or to develop antiproliferative drugs for PAH.

\section{Pathogenic genes and genome instability}

When nuclear DNA is damaged, normal cells initiate a response that includes cell cycle arrest, apoptosis and transcriptional induction of genes involved in DNA repair. The two tumour-suppressor genes, ataxiatelangiectasia mutated $(A T M)$ and p53, play a crucial role in responses to damaged DNA. In unstressed cells, p53 is negatively regulated by murine double minute 2 (MDM2) [44]. In atherosclerosis, as well as in primary aldosteronism, MDM2 is overexpressed, suggesting that MDM2 is important for pathological vascular remodelling [44-48]. Consistent with these observations, p53 gene deficiency in mice promotes hypoxia-induced $\mathrm{PH}$ and vascular remodelling [46], and activation of lung p53 by Nutlin-3a (a nongenotoxic activator of the p53 pathway) prevents and reverses experimental $\mathrm{PH}$ in mice [45]. Thus, evidence suggests that alterations in the MDM2-p53 interaction may also occur in human $\mathrm{PAH}$ and may partly contribute to senescence and apoptosis defects or to altered DNA damage or stress response. Genetic studies in familial cases of PAH have revealed heterozygous germline mutations in bone morphogenetic protein receptor 2 (BMPR2), a gene encoding a receptor for the transforming growth factor- $\beta$ superfamily $[49,50]$. Mutations in BMPR2 display a low penetrance $(\sim 20 \%)$ and have been reported in $>70 \%$ of subjects with familial history of PAH and in $11-40 \%$ of sporadic PAH. In addition to BMPR2, mutations in activin A receptor type II-like 1 (ACVRL1) [51], endoglin (ENG) [52], SMAD family member 9 (SMAD9) [53], caveolin-1 (CAV1) [54] and the potassium channel subfamily K, member 3 (KCNK3) [55] genes have recently been identified. Furthermore, a recent study has identified a susceptibility locus near CBLN2 
associated with a two-fold elevated risk of developing PAH [56]. Although evidence of monoclonality, somatic chromosome abnormalities together with instability of short DNA microsatellite sequences, has been obtained in PAH [8-10], some patients develop PAH in the absence of mutations in these pathogenic genes [57].

In contrast to PAH, genomic instability is a hallmark of cancer that leads to an increase in genetic alterations, thus enabling the acquisition of additional capabilities for carcinogenesis. In addition, a high degree of heterogeneity is often observed in the amount and type of instability within and between cancer types. However, it is also known that a significant number of carcinogens do not alter the structure of DNA (i.e. polypeptide and steroid hormones, specific dietary intake (methyl deficiency and galactosamine excess) and caloric intake) [58].

\section{Impaired angiogenesis and vasoreactivity}

Angiogenesis is critical for proper tissue development, homeostasis and function. Excessive (i.e. arthritis and diabetic retinopathy) and abnormal (chronic kidney disease and hereditary haemorrhagic telangiectasia) angiogenesis can lead to a large number of disease conditions. In experimental and human PAH, angiogenesis is clearly disturbed with loss and progressive obliteration of pre-capillary arteries leading to a pattern of vascular rarefaction ("dead-tree" picture) despite a high level of angiogenic factors, probably due to signalling defects in the endothelium in PAH [59-63]. Consistent with this notion, recent data from our group demonstrated increased pericyte coverage in distal pulmonary arteries in human PAH when compared with controls. In addition, we obtained evidence that this phenomenon is directly linked to pulmonary endothelial dysfunction, supporting the idea that future therapeutic strategies and agents should directly target one of these cell types that regulate both vascular tone and structure. In contrast to PAH, angiogenesis is essential for the growth and metastasis of solid tumours and represents a potential way for combating cancer $[64,65]$.

\section{Inflammation and dysimmunity}

Understanding of the inflammation associated with $\mathrm{PAH}$ has moved from a common histopathological curiosity to a key pathomechanism, which could be detrimental in terms of both disease susceptibility and development of pulmonary vascular remodelling. Several autoimmune and infectious diseases, such as systemic sclerosis, systemic lupus erythematous and HIV infection, are recognised causes of PAH [57, 66-68]. In addition, a recent study has described lymphoid neogenesis, a hallmark of autoimmune diseases, in detail in lungs from patients with idiopathic $\mathrm{PAH}$, which correlates with local autoantibody production. In this study, pulmonary tertiary lymphoid tissues were identified, ranging from small lymphoid aggregates to large accumulations of lymphocytes resembling highly to organised lymphoid follicles [69]. Thus, the presence of pulmonary tertiary lymphoid tissues in idiopathic PAH lungs could provide a structural basis for a local autoimmune response occurring in this apparently idiopathic disease. Further analyses of immunity in PAH support the notion that maladaptations of the immune response exist and may explain both this accumulation of perivascular inflammatory cells and the overabundance of cytokines and chemokines. Indeed, a delicate balance between immunity and tolerance exists and any disturbance may result in chronic inflammation or autoimmunity. Several types of autoantibodies directed against antinuclear antigens, endothelial cells and fibroblasts have been found in idiopathic and scleroderma-associated PAH [70-73]. These autoantibodies seem to play an important role for endothelial cell apoptosis and for the expression of cellular adhesion molecules [74-76], and we encourage further studies to characterise their pathogenic importance. The role of T-cells and, more specifically, regulatory T-cells (Treg) in the control of self-tolerance is well established [77-79] and it has been demonstrated that patients with PAH present altered Treg functions [42, 80]. As observed in $\mathrm{PAH}$, various types of immune and inflammatory cells are frequently present within tumours. It is now well established that inflammation increases cancer risk and affects every single step of carcinogenesis, as well as the response therapy [81]. However, given the complexity of these biological processes, additional insights into immune cells and key cytokines/chemokines are a prerequisite for a better understanding of disease immunopathology and, in turn, the development of novel therapeutic strategies.

\section{Conclusions and future visions}

In a certain way, PAH and cancer share several features, some stronger, others less so, including altered crosstalk between cells, abnormalities within various growth factor and mitogen-activated protein kinase stress-mediated pathways, metabolic (glycolytic) shifts, and the association with the immune system. However, the degrees of these analogous features in PAH are markedly different than those observed in cancer and neither local invasion nor metastasis are observed. Several targeted cancer therapies have been developed and interfere with proteins that are involved in cell signalling pathways that govern cell division, cell movement, cell death and the complex communication with the immune system. Therefore, further 
studies are needed to identify good targets in order to help identify the appropriate drugs for PAH. Future anti-proliferative strategies could offer a novel approach for the treatment of PAH, but the potential impacts of these anti-proliferative molecules on the adaptive response of myocardial hypertrophy will need to be evaluated cautiously.

\section{References}

1 Humbert M, Sitbon O, Chaouat A, et al. Survival in patients with idiopathic, familial, and anorexigen-associated pulmonary arterial hypertension in the modern management era. Circulation 2010; 122: 156-163.

2 O'Callaghan DS, Savale L, Montani D, et al. Treatment of pulmonary arterial hypertension with targeted therapies. Nat Rev Cardiol 2011; 8: 526-538.

3 Voelkel NF, Gomez-Arroyo J, Abbate A, et al. Pathobiology of pulmonary arterial hypertension and right ventricular failure. Eur Respir J 2012; 40: 1555-1565.

4 Rabinovitch M. Molecular pathogenesis of pulmonary arterial hypertension. J Clin Invest 2012; 122: 4306-4313.

5 Guignabert C, Dorfmuller P. Pathology and pathobiology of pulmonary hypertension. Semin Respir Crit Care Med 2013; 34: 551-559.

6 Rai PR, Cool CD, King JA, et al. The cancer paradigm of severe pulmonary arterial hypertension. Am J Respir Crit Care Med 2008; 178: 558-564.

7 Sakao S, Tatsumi K. Vascular remodeling in pulmonary arterial hypertension: multiple cancer-like pathways and possible treatment modalities. Int J Cardiol 2011; 147: 4-12.

8 Lee SD, Shroyer KR, Markham NE, et al. Monoclonal endothelial cell proliferation is present in primary but not secondary pulmonary hypertension. J Clin Invest 1998; 101: 927-934.

9 Yeager ME, Halley GR, Golpon HA, et al. Microsatellite instability of endothelial cell growth and apoptosis genes within plexiform lesions in primary pulmonary hypertension. Circ Res 2001; 88: E2-E11.

10 Aldred MA, Comhair SA, Varella-Garcia M, et al. Somatic chromosome abnormalities in the lungs of patients with pulmonary arterial hypertension. Am J Respir Crit Care Med 2010; 182: 1153-1160.

11 Tu L, De Man FS, Girerd B, et al. A critical role for p130Cas in the progression of pulmonary hypertension in humans and rodents. Am J Respir Crit Care Med 2012; 186: 666-676.

12 Tu L, Dewachter L, Gore B, et al. Autocrine fibroblast growth factor-2 signaling contributes to altered endothelial phenotype in pulmonary hypertension. Am J Respir Cell Mol Bio 2011; 45: 311-322.

13 Masri FA, Xu W, Comhair SA, et al. Hyperproliferative apoptosis-resistant endothelial cells in idiopathic pulmonary arterial hypertension. Am J Physiol Lung Cell Mol Physiol 2007; 293: L548-L554.

14 Xu W, Koeck T, Lara AR, et al. Alterations of cellular bioenergetics in pulmonary artery endothelial cells. Proc Natl Acad Sci USA 2007; 104: 1342-1347.

15 Tuder RM, Davis LA, Graham BB. Targeting energetic metabolism: a new frontier in the pathogenesis and treatment of pulmonary hypertension. Am J Respir Crit Care Med 2012; 185: 260-266.

16 Archer SL, Gomberg-Maitland M, Maitland ML, et al. Mitochondrial metabolism, redox signaling, and fusion: a mitochondria-ROS-HIF- $1 \alpha-\mathrm{Kv} 1.5 \mathrm{O}_{2}$-sensing pathway at the intersection of pulmonary hypertension and cancer. Am J Physiol Heart Circ Physiol 2008; 294: H570-H578.

17 McMurtry MS, Bonnet S, Wu X, et al. Dichloroacetate prevents and reverses pulmonary hypertension by inducing pulmonary artery smooth muscle cell apoptosis. Circ Res 2004; 95: 830-840.

18 Sutendra G, Bonnet S, Rochefort G, et al. Fatty acid oxidation and malonyl-CoA decarboxylase in the vascular remodeling of pulmonary hypertension. Sci Transl Med 2010; 2: 44 ra58.

19 Michelakis ED, McMurtry MS, Wu XC, et al. Dichloroacetate, a metabolic modulator, prevents and reverses chronic hypoxic pulmonary hypertension in rats: role of increased expression and activity of voltage-gated potassium channels. Circulation 2002; 105: 244-250.

20 Hanahan D, Weinberg RA. Hallmarks of cancer: the next generation. Cell 2011; 144: 646-674.

21 Hanahan D, Weinberg RA. The hallmarks of cancer. Cell 2000; 100: 57-70.

22 Ghofrani HA, Seeger W, Grimminger F. Imatinib for the treatment of pulmonary arterial hypertension. N Engl J Med 2005; 353: 1412-1413.

23 Souza R, Sitbon O, Parent F, et al. Long term imatinib treatment in pulmonary arterial hypertension. Thorax 2006; 61: 736 .

24 Ghofrani HA, Morrell NW, Hoeper MM, et al. Imatinib in pulmonary arterial hypertension patients with inadequate response to established therapy. Am J Respir Crit Care Med 2010; 182: 1171-1177.

25 Hoeper MM, Barst RJ, Bourge RC, et al. Imatinib mesylate as add-on therapy for pulmonary arterial hypertension: results of the randomized IMPRES study. Circulation 2013; 127: 1128-1138.

26 Humbert M. Impression, sunset. Circulation 2013; 127: 1098-1100.

27 Sonnenschein C, Soto AM. The aging of the 2000 and 2011 Hallmarks of Cancer reviews: a critique. J Biosci 2013; 38: 651-663.

28 Hopkins PN. Molecular biology of atherosclerosis. Physiol Rev 2013; 93: 1317-1542.

29 Che HL, Bae IH, Lim KS, et al. Suppression of post-angioplasty restenosis with an Akt1 siRNA-embedded coronary stent in a rabbit model. Biomaterials 2012; 33: 8548-8556.

30 Jiang Z, Shukla A, Miller BL, et al. Tumor necrosis factor- $\alpha$ and the early vein graft. J Vasc Surg 2007; 45: 169-176.

31 Bonta PI, Pols TW, de Vries CJ. NR4A nuclear receptors in atherosclerosis and vein-graft disease. Trends Cardiovasc Med 2007; 17: 105-111.

$32 \mathrm{Tu} \mathrm{L}$, Guignabert C. Emerging molecular targets for anti-proliferative strategies in pulmonary arterial hypertension. Handb Exp Pharmacol 2013; 218: 409-436.

33 McMurtry MS, Archer SL, Altieri DC, et al. Gene therapy targeting survivin selectively induces pulmonary vascular apoptosis and reverses pulmonary arterial hypertension. J Clin Invest 2005; 115: 1479-1491.

34 Izikki M, Guignabert C, Fadel E, et al. Endothelial-derived FGF2 contributes to the progression of pulmonary hypertension in humans and rodents. J Clin Invest 2009; 119: 512-523.

35 Merklinger SL, Jones PL, Martinez EC, et al. Epidermal growth factor receptor blockade mediates smooth muscle cell apoptosis and improves survival in rats with pulmonary hypertension. Circulation 2005; 112: 423-431. 
Schermuly RT, Dony E, Ghofrani HA, et al. Reversal of experimental pulmonary hypertension by PDGF inhibition. J Clin Invest 2005; 115: 2811-2821.

37 Guignabert $\mathrm{C}$, Tu L, Izikki $\mathrm{M}$, et al. Dichloroacetate treatment partially regresses established pulmonary hypertension in mice with SM22 $\alpha$-targeted overexpression of the serotonin transporter. FASEB J 2009; 23: 4135-4147.

38 de Man FS, Tu L, Handoko ML, et al. Dysregulated renin-angiotensin-aldosterone system contributes to pulmonary arterial hypertension. Am J Respir Crit Care Med 2012; 186: 780-789.

39 Dewachter L, Adnot S, Fadel E, et al. Angiopoietin/Tie2 pathway influences smooth muscle hyperplasia in idiopathic pulmonary hypertension. Am J Respir Crit Care Med 2006; 174: 1025-1033.

40 Eddahibi S, Guignabert C, Barlier-Mur AM, et al. Cross talk between endothelial and smooth muscle cells in pulmonary hypertension: critical role for serotonin-induced smooth muscle hyperplasia. Circulation 2006; 113: 1857-1864.

41 de Man FS, Handoko ML, Guignabert C, et al. Neurohormonal axis in patients with pulmonary arterial hypertension: friend or foe? Am J Respir Crit Care Med 2013; 187: 14-19.

42 Huertas A, Tu L, Gambaryan N, et al. Leptin and regulatory T-lymphocytes in idiopathic pulmonary arterial hypertension. Eur Respir J 2012; 40: 895-904.

43 Tian W, Jiang X, Tamosiuniene R, et al. Blocking macrophage leukotriene b4 prevents endothelial injury and reverses pulmonary hypertension. Sci Transl Med 2013; 5: 200 ra117.

44 Nakamura Y, Suzuki S, Suzuki T, et al. MDM2: a novel mineralocorticoid-responsive gene involved in aldosteroneinduced human vascular structural remodeling. Am J Pathol 2006; 169: 362-371.

45 Mouraret N, Marcos E, Abid S, et al. Activation of lung p53 by Nutlin-3a prevents and reverses experimental pulmonary hypertension. Circulation 2013; 127: 1664-1676.

46 Mizuno S, Bogaard HJ, Kraskauskas D, et al. p53 Gene deficiency promotes hypoxia-induced pulmonary hypertension and vascular remodeling in mice. Am J Physiol Lung Cell Mol Physiol 2011; 300: L753-L761.

47 Hashimoto T, Ichiki T, Ikeda J, et al. Inhibition of MDM2 attenuates neointimal hyperplasia via suppression of vascular proliferation and inflammation. Cardiovasc Res 2011; 91: 711-719.

48 Ihling C, Haendeler J, Menzel G, et al. Co-expression of p53 and MDM2 in human atherosclerosis: implications for the regulation of cellularity of atherosclerotic lesions. J Pathol 1998; 185: 303-312.

49 Machado RD, Pauciulo MW, Thomson JR, et al. BMPR2 haploinsufficiency as the inherited molecular mechanism for primary pulmonary hypertension. Am J Hum Genet 2001; 68: 92-102.

50 Lane KB, Machado RD, Pauciulo MW, et al. Heterozygous germline mutations in BMPR2, encoding a TGF-beta receptor, cause familial primary pulmonary hypertension. Nat Genet 2000; 26: 81-84.

51 Girerd B, Montani D, Coulet F, et al. Clinical outcomes of pulmonary arterial hypertension in patients carrying an ACVRL1 (ALK1) mutation. Am J Respir Crit Care Med 2010; 181: 851-861.

52 Chaouat A, Coulet F, Favre C, et al. Endoglin germline mutation in a patient with hereditary haemorrhagic telangiectasia and dexfenfluramine associated pulmonary arterial hypertension. Thorax 2004; 59: 446-448.

53 Shintani M, Yagi H, Nakayama T, et al. A new nonsense mutation of SMAD8 associated with pulmonary arterial hypertension. J Med Genet 2009; 46: 331-337.

54 Austin ED, Ma L, LeDuc C, et al. Whole exome sequencing to identify a novel gene (caveolin-1) associated with human pulmonary arterial hypertension. Circ Cardiovasc Genet 2012; 5: 336-343.

55 Ma L, Roman-Campos D, Austin ED, et al. A novel channelopathy in pulmonary arterial hypertension. $N$ Engl J Med 2013; 369: 351-361.

56 Germain M, Eyries M, Montani D, et al. Genome-wide association analysis identifies a susceptibility locus for pulmonary arterial hypertension. Nat Genet 2013; 45: 518-521.

57 Simonneau G, Robbins IM, Beghetti M, et al. Updated clinical classification of pulmonary hypertension. J Am Coll Cardiol 2009; 54: Suppl. 1, S43-S54

58 Pitot HC, Dragan YP. Facts and theories concerning the mechanisms of carcinogenesis. FASEB J 1991; 5: 2280-2286.

59 Li X, Zhang X, Leathers R, et al. Notch3 signaling promotes the development of pulmonary arterial hypertension. Nat Med 2009; 15: 1289-1297.

60 Merklinger SL, Wagner RA, Spiekerkoetter E, et al. Increased fibulin-5 and elastin in S100A4/Mts1 mice with pulmonary hypertension. Circ Res 2005; 97: 596-604.

61 Ryan J, Bloch K, Archer SL. Rodent models of pulmonary hypertension: harmonisation with the world health organisation's categorisation of human PH. Int J Clin Pract Suppl 2011; 172: 15-34.

62 Ritman EL. Micro-computed tomography of the lungs and pulmonary-vascular system. Proc Am Thorac Soc 2005; 2, 477-480: 501.

63 Le Cras TD, Kim DH, Gebb S, et al. Abnormal lung growth and the development of pulmonary hypertension in the Fawn-Hooded rat. Am J Physiol 1999; 277: L709-L718.

64 Jain RK, Carmeliet P. SnapShot: tumor angiogenesis. Cell 2012; 149: 1408-1408.

65 Bono F, De Smet F, Herbert C, et al. Inhibition of tumor angiogenesis and growth by a small-molecule multi-FGF receptor blocker with allosteric properties. Cancer Cell 2013; 23: 477-488.

66 Tcherakian C, Rivaud E, Zucman D, et al. Curing HIV-associated pulmonary arterial hypertension. Eur Respir J 2012; 39: 1045-1046.

67 Degano B, Guillaume M, Savale L, et al. HIV-associated pulmonary arterial hypertension: survival and prognostic factors in the modern therapeutic era. AIDS 2010; 24: 67-75.

68 Jaïs X, Launay D, Yaici A, et al. Immunosuppressive therapy in lupus- and mixed connective tissue diseaseassociated pulmonary arterial hypertension: a retrospective analysis of twenty-three cases. Arthritis Rheum 2008; 58 : 521-531.

69 Perros F, Dorfmüller P, Montani D, et al. Pulmonary lymphoid neogenesis in idiopathic pulmonary arterial hypertension. Am J Respir Crit Care Med 2012; 185: 311-321.

70 Dib H, Tamby MC, Bussone G, et al. Targets of anti-endothelial cell antibodies in pulmonary hypertension and scleroderma. Eur Respir J 2012; 39: 1405-1414.

71 Rich S, Kieras K, Hart K, et al. Antinuclear antibodies in primary pulmonary hypertension. J Am Coll Cardiol 1986; 8: $1307-1311$. 

associated pulmonary arterial hypertension. Thorax 2005; 60: 765-772.

73 Tamby MC, Humbert M, Guilpain P, et al. Antibodies to fibroblasts in idiopathic and scleroderma-associated pulmonary hypertension. Eur Respir J 2006; 28: 799-807.

74 Carvalho D, Savage CO, Black CM, et al. IgG antiendothelial cell autoantibodies from scleroderma patients induce leukocyte adhesion to human vascular endothelial cells in vitro. Induction of adhesion molecule expression and involvement of endothelium-derived cytokines. J Clin Invest 1996; 97: 111-119.

75 Bordron A, Dueymes M, Levy Y, et al. The binding of some human antiendothelial cell antibodies induces endothelial cell apoptosis. J Clin Invest 1998; 101: 2029-2035.

76 Arends SJ, Damoiseaux JG, Duijvestijn AM, et al. IgG anti-endothelial cell antibodies: inducers of endothelial cell apoptosis in pulmonary arterial hypertension? Clin Exp Immunol 2013 [in press DOI: 10.1111/cei.12166]. 77 Sakaguchi S. Naturally arising CD4+ regulatory T cells for immunologic self-tolerance and negative control of
immune responses. Ann Rev Immunol 2004; 22: 531-562.

78 Kim JM, Rasmussen JP, Rudensky AY. Regulatory T cells prevent catastrophic autoimmunity throughout the lifespan of mice. Nat Immunol 2007; 8: 191-197.

79 Nishizuka Y, Sakakura T. Thymus and reproduction: sex-linked dysgenesia of the gonad after neonatal thymectomy in mice. Science 1969; 166: 753-755.

80 Tamosiuniene R, Tian W, Dhillon G, et al. Regulatory T cells limit vascular endothelial injury and prevent pulmonary hypertension. Circ Res 2011; 109: 867-879.

81 Grivennikov SI, Greten FR, Karin M. Immunity, inflammation, and cancer. Cell 2010; 140: 883-899. 